\title{
Guerra: modernidad y contramodernidad
}

\author{
Pablo Augusto Bonavena y Flabián Nievas \\ Editorial Final Abierto. Buenos Aires, 2015. \\ 26 i páginas.
}

U no de los elementos esenciales que justifica el trabajo e invita a su lectura, es que generalmente se toma nota de los daños materiales que produce la violencia, pero "pocas veces se señala su incidencia en los entramados de relaciones sociales” (p.40). Aun así, el texto no se limita a lo sociológico, sino que abre el abanico, generando preguntas inquietantes, en especial respecto de lo político, económico, estratégico y social.

Presenta las conclusiones de tres años de investigación sobre la Guerra, abordada por diez sociólogos financiados por la Universidad de Buenos Aires (Proyecto UBACyT W-9I3). Los autores del libro, Pablo Bonavena y Flabián Nievas, argumentan en favor de la necesidad de que los científicos sociales se involucren "en el estudio de un fenómeno en apariencia tan lejano, y tan cercano en la práctica, como la guerra" (p. 6).

La lectura invita a poner en escrutinio la situación de paz relativa en el Cono Sur. Anotemos, además, que el escenario de seguridad internacional atestigua la expansión de los conflictos armados en la región, desde que Colombia comienza a tener éxito en la lucha contra las narco-guerrillas. La violencia se ha expandido hacia el norte por América Central y México, y al sur pasando por Ecuador y Perú; tal vez es apenas una cuestión de tiempo hasta que el flagelo golpee la puerta de nuestra subregión. Pero, ¿qué tipo de lucha es la que se expande? ¿O es nuestra percepción de inseguridad la que se agudiza con la cobertura mediática de la prensa y títulos de ficción en formato de seriales de televisión?

El texto revisa la historia de lo que entendemos como guerra interestatal. Es decir, en su manifestación clásica de hostilidades entre Estados. Posteriormente, da cuenta de las variaciones del fenómeno a partir de la segunda mitad del siglo xx, tras lo cual alerta del 
rumbo que sigue "un tema generalmente subvalorado" (p.7). Finalmente, incluye un análisis prospectivo. Su principal conclusión es que "el sistema que conocimos y sobre el que están fundados nuestros valores y nuestras categorías cognitivas, parece estar transformándose de manera definitiva" (p.7). El libro provee los ingredientes necesarios para demostrar que esta apreciación es acertada.

A juicio de los autores, los datos de la transformación del fenómeno guerra, desde la modernidad a nuestros días, permiten referirse ahora a la guerra de la contramodernidad como un fenómeno distintivo de la guerra moderna. Sin embargo, a partir de la lectura, es posible interpretar que desde un punto de vista estratégico, la guerra de la contramodernidad no es más que el resultado del proceso de adaptación del pensamiento estratégico a los esfuerzos de la comunidad internacional por institucionalizar la paz. Las mutaciones que el belicismo muestra en la actualidad reflejan el éxito de los esfuerzos por forjar estructuras sólidas que actúen como un freno a la violencia, pero que a la vez permiten advertir que en la natural dialéctica del conflicto siempre será posible buscar maneras de ejercer la violencia mientras exista la voluntad de hacerlo. Al respecto, es pertinente señalar que la lectura de Guerra: modernidad y contramodernidad se complementa muy bien con textos dedicados a la guerra irrestricta, pensamiento estratégico que plasma un cambio en la forma de pensar la guerra misma. Ambos nos incitan a revalorar la oportuna resolución de conflictos. Clave es abordarlo en sus manifestaciones incipientes.

En el recuento histórico se echa de menos la lectura de Mao y los hechos que caracterizan su lucha nacional. En especial porque su pensamiento estratégico es el que abre la perspectiva a que las fuerzas irregulares de lucha generen una forma de combate efectiva, capaz de alcanzar la victoria. En la década de 1930, Mao produce un cambio de enfoque determinante cuando descarta la posibilidad de alcanzar una victoria militar con fuerzas no convencionales. En vez, propone centrar el esfuerzo de lucha en convencer al adversario que sus metas estratégicas son inalcanzables. El tiempo demuestra que es posible derrotar a un adversario con mayor poder económico y militar, teniendo como instrumento esencial una voluntad 
política superior. Los actores no estatales vislumbran aquí la posibilidad a privatizar la violencia, que se pone en práctica por fuerzas rebeldes, anticoloniales o incluso bandas criminales que actúan en contra del Estado.

De particular interés son los párrafos escritos en contra de la tortura, dando cuenta en forma muy contundente y sintética, del rol que cumple la aplicación de esta técnica en el derrumbe del sistema jurídico penal, a nivel nacional e internacional (pp. I86-I87). También destacan las líneas dedicadas al ejercicio de la inteligencia y las posibilidades que brinda la ausencia de límites técnicos para practicarla. Advirtiendo que las posibilidades de monitoreo de las personas son múltiples, los autores reconocen que el límite de observación se encuentra en la capacidad de administrar datos. Aclaran (p.2I2):

...no es que todos sean vigilados, sino que cualquiera, en el momento que se requiera, puede ser monitoreado $y$, eventualmente, acusado o eliminado debido a evidencias circunstanciales. Se trata de un entramado de control flexible, cuya gestión no es estatal ni empresarial pura, pero tampoco del Estado y empresas asociadas como tales, sino de una mixtura aún indefinible, que licúa nuevamente la distinción entre lo público y lo privado.

En síntesis, se trata de una lectura necesaria y recomendable, no solo por el contenido sino que por una fluida redacción, muy amigable para entrar en materia.

\section{POR Cristián Faundes}

Centro de Estudios Estratégicos

Academia de Guerra, Ejército de Chile 